\title{
Use of Alternative Fuels and Hybrids by Small Urban and Rural Transit
}

\author{
Jeremy Mattson \\ North Dakota State University
}

\begin{abstract}
To better understand the problems and benefits of using biodiesel, E85, propane, natural gas, and hybrid vehicles in smaller communities, a survey of 115 small urban and rural transit agencies was conducted. This study describes the use of alternative fuels and hybrids by these transit providers; identifies motivating factors and deterrents for adoption; describes the experience of transit agencies that have adopted these alternatives, including costs, maintenance, reliability, and overall satisfaction; and examines differences between those agencies that use these alternatives and those that do not, as well as differences between rural and small urban areas. Larger agencies and those operating in urban areas were found to be more likely to adopt alternatives than smaller, rural providers. Beliefs about the benefits of emissions reductions, improved public perception, and cost savings were the greatest motivating factors for adoption, and concerns about infrastructure costs and fuel supply were the most likely to negatively influence adoption.
\end{abstract}

\section{Introduction}

Transit agencies of all sizes across the U.S. have been or are considering using hybrid-electric vehicles or alternative fuels such as biodiesel, compressed natural gas (CNG), propane, or E85. The use of these alternatives has increased in recent years due to concerns about environmental and energy issues and increased incentives and regulations from local, state, and federal governments that have encour- 
aged their use. Benefits to transit agencies for using alternative fuels and hybrids have been documented in terms of reduced emissions of harmful pollutants, such as carbon monoxide (CO), nitrogen oxides (NOx), particulate matter (PM), and hydrocarbons (HC) (FTA 2006; FTA 2007; Nylund et al. 2004). A reduction in lifecycle greenhouse gas (GHG) emissions has also been found (FTA 2007; EPA 2007; Beer et al. 2002). On the other hand, a number of barriers have prevented widespread adoption, including higher capital costs of vehicles and supporting facilities, reliability concerns, and limited availability of alternative fuels (FTA 2006).

Transit agencies have been leaders in using alternative fuel vehicles. Smaller transit agencies, including those operating in small urban and rural areas, however, may face greater difficulties in making the transition. Infrastructure or capital costs could be prohibitively expensive, or the agencies could lack the resources and expertise to successfully operate these vehicles. Furthermore, the supply of vehicles designed to meet their standards could be limited, as could an adequate and dependable supply of the fuel. Reliability and maintenance issues could also be a concern for smaller agencies that could face significant disruptions in service if any of their vehicles were out of service.

Small urban and rural transit agencies need to be fully informed of the costs and benefits of alternative fuels and hybrid vehicles before adoption, and they can learn from the experiences of those that have been using these alternatives. Decision makers also need to understand the needs and concerns of transit agencies. While previous research has identified advantages and disadvantages from using alternative fuels and hybrid buses, less is known about the factors that motivate agencies to adopt these alternatives or the degree to which different deterrents are preventing adoption, especially among small urban and rural transit agencies.

A survey was conducted of small urban and rural transit agencies to learn more about these motivating factors and the experiences of transit systems. The survey focused on biodiesel, E85, propane, natural gas, and hybrid-electric vehicles. It asked users to identify their motivations for adoption, concerns before adoption, overall satisfaction, and problems experienced. Non-users were asked to identify deterrents to adoption and potential benefits from adoption. A logit model was estimated to determine the impacts of agency characteristics and beliefs about benefits and deterrents on the likelihood of adopting biodiesel or hybrid vehicles. An ordered logit model was also estimated to determine the characteristics of agencies more likely to have successful experiences with biodiesel. The findings 
provide useful information to policy makers and transit operators considering adoption.

\section{Survey Design, Administration, and Response}

The survey was targeted toward transit providers in small urban or rural areas. Small urban providers were defined as those receiving Section 5307 funding and operating in areas with a population below 200,000, and rural providers were defined as those receiving Section 5311 funding. A list of small urban transit agencies was obtained from the 2008 National Transit Database (NTD). Using the NTD, 394 small urban transit systems were identified. Contact names and email addresses were found for 305 of these transit agencies.

The survey was also targeted to 270 rural transit agencies, which represented the largest 20 percent of section 5311 providers measured in terms of vehicle miles of service as reported in the 2009 rural NTD. The survey was limited to the larger rural systems, since many of the smaller rural operators may not be considering alternative fuels and hybrids, and there was a concern about getting a poor response rate from these agencies, as well as significant self-selection bias. Contact information, which was developed previously for a survey by Ripplinger and Brandt-Sargent (2010), was available for 245 of these 270 agencies. Combined, the survey was sent to 550 transit providers.

The survey was administered online. E-mail invitations were sent to transit agencies with a link to the survey. The original e-mail invitation was sent on March 29, 2011, and a reminder e-mail was sent eight days later. The survey was kept open until the end of April. Of the 550 e-mail invitations sent, 56 were returned undeliverable, possibly due to outdated contact information, which left 494 transit agencies that received the survey. A total of 115 responses were received, yielding a response rate of 23 percent. The full survey and complete results can be found in Mattson (2012).

\section{Agency Characteristics}

Survey results were received from transit agencies in 36 states. Fifty-four of the responding agencies were from small urban areas, and 37 were rural transit operators (the remaining respondents did not identify their location). Additional data from the NTD were used to identify characteristics of responding agencies for those that provided their location or name of agency. These agencies provided an average of 1.1 million vehicle revenue miles, 64,000 vehicle revenue hours, and 
913,000 trips in 2009. Median values for these agencies were 733,000 vehicle miles, 45,000 vehicle hours, and 367,000 trips.

For the small urban systems, about two-thirds of the vehicle miles provided was for fixed-route service, while about one-third of vehicle miles for the rural systems was for fixed-route service. The small urban systems provided an average of 1.29 trips per mile while traveling 13.7 miles per hour, compared to rural systems that provided an average of 0.25 trips per mile at 28.0 miles per hour. The rural agencies tend to travel at higher speeds and travel more miles per trip. These differences may influence an agency's decision to use an alternative fuel or hybrid vehicle.

Biodiesel is the most commonly-used alternative fuel among small urban and rural transit operators. Thirty-one of the responding agencies use biodiesel, while 10 use CNG, 8 use E85, 4 use propane, and 24 own hybrid-electric vehicles. Among biodiesel users, about half use a $20 \%$ blend at least some of the time, while the remainder uses a lower blend.

\section{Perceived Benefits and Deterrents}

Reducing emissions, energy dependency concerns, political directives, improving public perception, and fuel cost savings were common motivating factors for agencies that have adopted alternative fuels or hybrids. Reducing emissions was commonly mentioned as a major reason for adopting hybrids ( 16 out of 24 respondents) or CNG vehicles (8 out of 10), but it was more often noted as a minor reason for adopting biodiesel. Similarly, a greater percentage of hybrid users mentioned energy dependency concerns (11 of 22) and improving public perception (16 of 23) as a major reason for adoption than did biodiesel users. (Of 21 responding biodiesel users, 6 considered energy dependency concerns a major reason and 5 considered improving public perception a major reason.) Responses regarding energy dependency suggest that public transportation agencies are becoming more sensitive to their role as energy consumers and are seeking ways to help reduce the nation's dependence on fossil fuels and oil imported from other countries.

Fuel cost savings was also a major reason most hybrid users (19 of 24), and half of CNG users adopted those vehicles, while fuel cost savings was not a motivating factor for biodiesel use. Political directives were cited as a major reason for 9 of 22 biodiesel users and 10 of 23 hybrid users.

For agencies that have not used alternative fuels or hybrids, deterrents differed for each alternative. The major findings were as follows: 
- Fuel cost was found to most likely be a deterrent for biodiesel (25 of 56 respondents called it a major deterrent).

- Fuel mileage was often considered (33\% of non-users) a major deterrent for E85, and some agencies (18\%) also considered it a major deterrent for biodiesel.

- One of the most significant deterrents for adopting alternative fuels and hybrids was concern with maintenance issues. This was commonly mentioned as a major deterrent for all alternatives ( $49 \%$ of biodiesel non-users, $29 \%$ of E85 non-users, $45 \%$ of propane non-users, $47 \%$ of CNG non-users, and $45 \%$ of hybrid non-users). Some agencies (31\%) were also concerned about fuel quality as a major problem for biodiesel.

- Lack of an adequate and dependable fuel supply was a major deterrent for all alternative fuels. This was listed as a major deterrent for about half of E85, propane, and natural gas non-users and two-thirds of biodiesel non-users.

- Lack of information was considered a major deterrent for about one fourth to one third of agencies, regardless of the alternative.

- Overall performance was most likely to be considered a deterrent for hybrid vehicles, as 28 of 66 non-users considered vehicle performance to be a major deterrent.

- Vehicle availability was a major deterrent for 45 percent of agencies for hybrids and 42 percent of agencies for propane vehicles. It was considered less of a deterrent for E85 and was not a deterrent for biodiesel use.

- Vehicle cost was the greatest deterrent for use of hybrids (78\% of respondents called it a major deterrent) and also one of the most significant deterrents for propane and natural gas use (64\% and $60 \%$ of propane and natural gas users, respectively, cited it as a major deterrent).

- Development and implementation of new fuel infrastructure and modifications to maintenance facilities were the greatest deterrents for use of propane and natural gas, as about three-quarters of respondents referred to these as major deterrents. Over half of respondents also considered infrastructure cost as a major deterrent for biodiesel.

- Safety hazards and limited vehicle range were considered major deterrents by a significant number of agencies for adopting propane (38\% and $43 \%$, respectively) or natural gas (37\%). 


\section{Experiences of Alternative Fuel and Hybrid Users}

The experiences of agencies that have adopted these alternatives can differ from the expectations or perceptions of non-users. For those agencies that use these alternative fuels or hybrids, fuel cost was most likely to be a problem for biodiesel (32\% called it a major problem) or E85. Maintenance issues were more likely to be a major problem for biodiesel (23\%). For all alternatives, though, a majority of users experienced no maintenance problems, and many of the problems encountered were minor. The responses regarding reliability were similar, with the greatest problems being for biodiesel (19\% called it a major problem). Adequate and dependable fuel supply was most likely to be a problem for E85 ( 1 of 6 users called it a major problem and 4 cited it as a minor problem). Most of the fuel supply problems for E85 and other fuels were considered minor. Overall, users of alternative fuels and hybrids tend to be satisfied (Table 1).

Table 1. Satisfaction Reported with Each Alternative Fuel and Hybrid

\begin{tabular}{|l|c|c|c|c|c|c|}
\cline { 2 - 7 } \multicolumn{1}{c|}{} & N & $\begin{array}{c}\text { Very } \\
\text { Satisfied }\end{array}$ & $\begin{array}{c}\text { Somewhat } \\
\text { Satisfied }\end{array}$ & $\begin{array}{c}\text { Neither Satisfied } \\
\text { nor Dissatisfied }\end{array}$ & $\begin{array}{c}\text { Somewhat } \\
\text { Dissatisfied }\end{array}$ & $\begin{array}{c}\text { Very } \\
\text { Dissatisfied }\end{array}$ \\
\hline Biodiesel & 22 & $27 \%$ & $36 \%$ & $14 \%$ & $18 \%$ & $5 \%$ \\
\hline E85 & 7 & $29 \%$ & $0 \%$ & $57 \%$ & $14 \%$ & $0 \%$ \\
\hline Propane & 4 & $0 \%$ & $75 \%$ & $25 \%$ & $0 \%$ & $0 \%$ \\
\hline CNG & 9 & $56 \%$ & $44 \%$ & $0 \%$ & $0 \%$ & $0 \%$ \\
\hline Hybrid-electric & 24 & $50 \%$ & $17 \%$ & $8 \%$ & $8 \%$ & $17 \%$ \\
\hline
\end{tabular}

Cold weather performance is often considered a major deterrent for use of biodiesel, especially in colder climates. A survey of state DOTs by Humberg et al. (2006) found that the most common deterrent for biodiesel adoption, besides cost, was concerns about cold weather performance, but cold weather behavior was not found to be a widespread problem for those state transportation agencies that had adopted the fuel. Our study found similar results. Among the responding agencies that use biodiesel, 48 percent considered cold weather performance to be a major concern before adoption, but just 23 percent have considered it a major problem since adoption. Still, it is an issue to contend with. Most transit providers in northern states switch to a lower blend in the winter.

Transit agencies most satisfied with E85 use the fuel more often. For example, of the three that use E85 more than 90 percent of the time, two were very satisfied with it. The most satisfied CNG users have been using the fuel longer, more than 10 years. 
Overall, most hybrid users have not experienced problems greater than what they have experienced with conventional vehicles, with some exceptions. Many plan to purchase additional hybrids within the next five years. The most significant concerns were the additional vehicle costs and whether users in rural areas would ever achieve any savings.

In many cases, agencies were more likely to view an issue as being problematic before adoption than to actually experience the problem afterwards. This is especially observed for biodiesel users regarding maintenance issues, cold weather performance, and fuel quality. Fuel cost was the one issue biodiesel users were more likely to find problematic than they expected. Four of these agencies using E85 considered adequate and dependable fuel supply as a major deterrent, but only one listed it as a major problem since adoption. Similarly, two E85 users considered maintenance issues as a major concern before adoption, but none said it was a major problem after adoption. Reported problems for hybrid users were also not as great as the concerns reported before adoption.

Regarding fuel economy, 18 of 24 respondents using hybrids have noted an increase in miles per gallon, ranging from a 10 percent to 40 percent increase. Most biodiesel users had not noticed a change in fuel efficiency. Three of 20 biodiesel users noticed small decreases in miles per gallon.

\section{Differences between Users and Non-Users}

Larger agencies and those operating in urban areas tend to be more likely to adopt alternatives than smaller, rural providers. Eighty-six percent of biodiesel and hybrid users responding to the survey are located in urban areas, and 78 percent of CNG users are urban. Agencies using biodiesel provide 50 percent more vehicle miles of service and nearly four times as many trips as those that do not use biodiesel. Similar comparisons can be made between hybrid users and non-users. Biodiesel, propane, CNG, and hybrid users also tend to run mostly fixed-route systems with a smaller percentage of demand response.

As some of the respondents noted, rural agencies are less likely to benefit from hybrid technologies since they provide longer trips at higher speeds with less stopand-go travel. Urban driving, with repeated acceleration and braking combined with modest speeds, is more favorable for hybrid drive systems. The recapture of energy through regenerative braking is more efficient under urban driving conditions. Research has shown that the fuel consumption savings and emissions reduc- 
tions from hybrids are small in rural areas and almost non-existent on highways, where the electric motor is hardly able to offer any additional support to the internal combustion engine (Alvarez et al. 2010). The characteristics of adopters reflect this argument. In addition to being mostly urban, fixed-route service, agencies with hybrid vehicles provide more trips per mile and per hour and travel fewer miles per hour than those transit providers without hybrid vehicles.

Not all of the differences between users and non-users can be explained by agency characteristics, however. Differences in individual attitudes and beliefs regarding perceived benefits and deterrents could also explain some differences.

\section{Perceived Benefits}

In general, users of alternative fuels and hybrids were more likely to identify benefits of adoption. For example, 71 percent of biodiesel users thought that improving public perception was a major benefit, compared to just 31 percent of non-users. E85 users were much more likely to view use of local resources and products as a major benefit ( $43 \%$ vs. $14 \%$ ). Therefore, transit agencies located in areas where ethanol is produced could be more likely to use the fuel. In fact, four of the eight respondents using E85 are located in lowa.

CNG users were more likely than non-users to view reducing emissions ( $80 \%$ vs. $53 \%$ ), improving public perception ( $60 \%$ vs. $41 \%$ ), and fuel cost savings ( $50 \%$ vs. $31 \%)$ as major benefits. Non-users were actually more likely to view positive performance impacts of the fuel as a major benefit. For hybrids, the most significant difference was that users were more likely to view improved public perception (70\% vs. $53 \%$ ) and fuel cost savings ( $79 \%$ vs. $57 \%$ ) as major benefits, suggesting that these were motivating factors for the purchase of hybrid-electric vehicles.

\section{Deterrents}

Users and non-users also perceive some of the deterrents differently. For biodiesel, the most significant differences were regarding infrastructure costs and fuel supply. Fifty-three percent of non-users viewed infrastructure costs as a major deterrent to using biodiesel, compared to just 5 percent of users. Since there are no additional infrastructure costs required to adopt biodiesel, this result suggests non-users of biodiesel misperceive that they would have to modify their fueling equipment or vehicle engines to use the fuel. Two-thirds of non-users viewed the lack of an adequate and dependable fuel supply as a major deterrent compared to 19 percent of biodiesel users. Fuel supply may be a legitimate deterrent for wide-scale adoption, 
and these findings suggest that those transit providers in areas where biodiesel is more readily available are more likely to use the fuel.

For CNG, non-users were significantly more likely than users to view high vehicle cost ( $60 \%$ vs. $11 \%)$, development and implementation of new fuel infrastructure ( $79 \%$ vs. $33 \%$ ), modifications to maintenance facilities ( $73 \%$ vs. $11 \%$ ), adequate and dependable fuel supply ( $48 \%$ vs. $11 \%$ ), and maintenance issues ( $47 \%$ vs. $0 \%$ ) to be major deterrents. These perceived differences could be real or due to a lack of information, but actual differences in infrastructure and modification costs exist. CNG is more popular in warmer climates where fueling is performed outdoors with minimal infrastructure required to meet fire codes. In colder climates, where all bus storage, maintenance, and fueling operations occur indoors, the cost of retrofitting an existing facility for CNG to meet fire code requirements may be prohibitive. Many of the CNG users responding to the survey are from southern states, including four from California.

Regarding hybrid vehicles, non-users were found to be consistently more likely to view an issue as a deterrent than were those agencies that have purchased hybrids. Results suggest that some issues such as vehicle availability, depot modification costs, concerns about reliability and vehicle performance, and battery replacement costs could explain some of the differences between those agencies that have purchased hybrids and those that have not.

\section{Differences between Urban and Rural Transit Providers}

Rural transit providers may have different problems or challenges and may view the benefits differently. As noted, many of the responding agencies that use alternative fuels or hybrid vehicles are from urban areas. For example, 38 percent of urban agencies surveyed use biodiesel, compared to 12 percent of rural transit providers. Similarly, 35 percent of urban respondents operate a hybrid vehicle, compared to 8 percent of rural respondents. One exception is E85. Urban and rural providers are about equally likely to own a flex fuel vehicle, but the rural respondents were found to be more likely to use E85 in those vehicles.

Urban and rural transit providers face many of the same deterrents and have many of the same opinions on benefits and problems, but some differences exist. Adequate and dependable fuel supply was found to be a major deterrent for both urban and rural providers, but it is a greater issue for those transit agencies serving rural areas. Seventy-five percent of rural respondents cited it as a major deter- 
rent for using biodiesel, compared to 46 percent of urban respondents. Similar responses were obtained for E85 (70\% of rural respondents and $53 \%$ of urban), propane (69\% rural, $35 \%$ urban), and CNG (61\% rural, 35\% urban). In each case, rural respondents were also more likely to indicate that lack of information is a major deterrent. Limited vehicle range was also a greater issue for rural transit providers regarding propane and CNG, making long-distance trips difficult. Vehicle range and limited access to fueling infrastructure were previously documented to be issues for rural providers using propane or natural gas vehicles in Texas (TTI 2007). In general, rural respondents were more likely to report deterrents for all alternatives.

Regarding benefits, urban respondents were consistently more likely to say that improving public perception is a major benefit. Rural respondents were generally more likely than their urban counterparts to identify benefits from using biodiesel and E85 but tended to be less likely to find benefits from using propane, CNG, or hybrids.

\section{Factors Affecting Adoption}

To investigate how agency characteristics or beliefs about benefits and deterrents have influenced adoption of biodiesel or hybrid vehicles, a binary logit model was used. The binary logit model is a type of discrete choice model that can be used to model an agency's decision to adopt technology (Ripplinger and Brandt-Sargent 2010). We assume that transit agencies make the decision to adopt technology based on its impact on social welfare. Social welfare, $W$, is a function of consumer surplus (CS), which is affected by various factors, $X$, and the technology employed by the transit agency, $\tau$, and the profits of the agency, $\pi$, which are affected by another set of factors, $Z$, and technology, $\tau$, as shown by Equation 1 .

$$
\mathrm{W}_{\mathrm{i}}=\mathrm{CS}(\mathrm{X}, \tau)+\pi_{\mathrm{i}}(\mathrm{Z}, \tau)
$$

Using biodiesel or hybrid vehicles influences cost effectiveness by impacting costs paid for fuel, infrastructure, vehicles, maintenance, etc. They also impact the social cost of operating transit vehicles by reducing negative environmental externalities, such as air pollution, and thereby affect social welfare. An agency's perception about the benefits of an alternative fuel will influence how they perceive social welfare will be impacted by the use of that type of alternative fuel or vehicle. Results from the survey suggest that these factors influence the decision to adopt.

Two separate binary logit models were estimated for biodiesel and hybrid vehicle adoption. The dependent variable is a binary variable equal to one if the agency 
uses biodiesel or hybrid vehicles and zero otherwise. Adoption of E85, propane, or CNG was not modeled because not enough users of these fuels responded to the survey, so there were not enough observations to develop a model.

Explanatory variables include characteristics of the agency and opinions about benefits and deterrents. Agency characteristics that could influence adoption include the number of vehicles the agency owns, the number of vehicles miles of service provided, the number of vehicle hours of service provided, and whether they serve a rural or small urban area. It is expected that larger agencies, those with more vehicles, and those providing more miles and hours of service are more likely to use biodiesel or hybrid vehicles, and those in urban areas may also be more likely to adopt these alternatives. Larger agencies may be more likely to have the resources to consider and adopt these alternatives, and the benefits of hybrid technology are more advantageous in urban driving conditions.

It is also hypothesized that those agencies that identify greater benefits of biodiesel or hybrid adoption, such as emissions reductions or improved public perception, are more likely to choose those alternatives. Likewise, those that identify greater deterrents, such as increased costs or inadequate supply, are hypothesized to be less likely to adopt. Dummy variables are included in the model to represent respondents who considered a potential benefit as a major benefit or a potential deterrent as a major deterrent.

The estimated odds ratios from the binary logit models are shown in Table 2. Agency size variables were measured as the number of vehicles the agency operates and the thousands of miles and hours of service provided. The odds ratio for these variables is the estimated change in the odds of adoption with a one unit increase in the variable.

Results show that agencies that operate more vehicles and provide more vehicle miles of service were more likely to use biodiesel. Conversely, those that provide more hours of service, everything else held constant, were less likely to use biodiesel, indicating that agencies were less likely to use biodiesel if their service was spread out over more hours. In other words, those agencies providing more miles of service per hour were more likely to use biodiesel. The impacts of vehicles, vehicle miles, and vehicles hours on hybrid use were not found to be statistically significant. 
Table 2. Results from Binary Logit Models of Adoption

\begin{tabular}{|l|c|c|c|c|}
\cline { 2 - 5 } \multicolumn{1}{c|}{} & \multicolumn{2}{c|}{ Biodiesel } & \multicolumn{2}{c|}{ Hybrids } \\
\cline { 2 - 5 } \multicolumn{1}{c|}{} & OR & $\mathbf{9 5 \%} \mathbf{C l}$ & OR & $\mathbf{9 5 \% ~ C l}$ \\
\hline Vehicles (number) & $1.067^{* * *}$ & $1.021-1.116$ & 1.016 & $0.983-1.049$ \\
\hline Vehicle miles (thousand) & $1.001^{*}$ & $1.000-1.002$ & 1.000 & $1.000-1.001$ \\
\hline Vehicle hours (thousand) & $0.959^{* *}$ & $0.925-0.995$ & 0.994 & $0.973-1.015$ \\
\hline Urban & $74.698^{* *}$ & $1.367-999.9$ & $8.420^{*}$ & $0.948-74.76$ \\
\hline
\end{tabular}

Perceived benefits
\begin{tabular}{|l|c|c|c|c|}
\hline Emissions & $32.043^{* *}$ & $1.532-670.3$ & 1.343 & $0.183-9.850$ \\
\hline Energy dependency & 0.322 & $0.033-3.122$ & $0.146^{*}$ & $0.018-1.165$ \\
\hline Local resources & 0.525 & $0.034-8.138$ & & \\
\hline Public perception & $33.154^{* * *}$ & $3.080-356.9$ & $4.890^{*}$ & $0.762-31.37$ \\
\hline Cost savings & 0.525 & $0.008-8.069$ & $5.113^{*}$ & $0.728-35.92$ \\
\hline
\end{tabular}

Deterrents

\begin{tabular}{|l|c|c|l|l|}
\hline Fuel cost & 0.718 & $0.091-5.676$ & & \\
\hline $\begin{array}{l}\text { Infrastructure cost/ } \\
\text { Depot modification cost }\end{array}$ & 0.119 & $0.004-3.436$ & $0.090^{* *}$ & $0.010-0.840$ \\
\hline Fuel supply & $0.061^{*}$ & $0.003-1.069$ & & \\
\hline Lack of information & 0.913 & $0.016-53.44$ & & \\
\hline Fuel efficiency & 0.775 & $0.020-30.43$ & & \\
\hline Vehicle cost & & & 0.635 & $0.149-2.712$ \\
\hline $\mathrm{n}=86$ & & & & \\
\hline
\end{tabular}

Note: $\mathrm{OR}=$ odds ratio; $\mathrm{Cl}=$ confidence interval.

${ }^{*} p<0.10{ }^{* *} p<0.05^{* * *} p<0.01$

Urban agencies were substantially more likely to use biodiesel (odds ratio 74.70) and hybrids (odds ratio 8.42). The odds of using biodiesel were 75 times greater, and the odds of adopting hybrids was 8.4 times greater if the agency operates in an urban area, everything else held constant.

Agencies that viewed emissions reductions as a major benefit of biodiesel were significantly more likely to use that fuel. Agencies that viewed reducing energy dependency as a major benefit of hybrid use were actually less likely to use hybrids, though the result was only marginally significant. In either case, the implication is that concerns about energy dependency do not motivate agencies to adopt either biodiesel or hybrids, even though some view biodiesel or hybrids as being benefi- 
cial in this regard. Agencies that consider improved public perception as a major benefit were significantly more likely to use biodiesel or hybrids. This result is especially significant for biodiesel. It appears counterintuitive that energy dependency concerns are not a significant determinant of adoption, while improving public perception is significant. One possible explanation is that whether or not they believe energy independence is important or if their decision to adopt will have a positive impact on reducing dependency on imported oil, transit agencies are more likely to be motivated by public perception.

Those who view fuel cost savings as a major benefit for hybrids were significantly more likely to use those vehicles. Findings show that beliefs about the benefits of emissions reductions, improved public perception, and costs savings are the greatest motivating factors for adoption.

Regarding deterrents, two significant results were found. Those agencies that listed depot modification costs as a major deterrent for hybrid use were significantly less likely to adopt, and those that cited lack of adequate and dependable fuel supply as a major deterrent for biodiesel adoption were significantly less likely to use that fuel. While other deterrents exist, the model did not find significant differences between users and non-users regarding their perceptions of those deterrents. Perhaps more significant results would be found with a greater number of observations. These results indicated that concerns about infrastructure costs and fuel supply were most likely to influence the decision to adopt biodiesel or hybrids. Whether these perceptions are valid and decisions are rational is another matter. Some perceptions may be correct while others are not. Since hybrids usually do not require significant facility modifications, the results suggest hybrid non-users could be misperceiving required infrastructure costs.

\section{Factors Affecting Satisfaction with Biodiesel}

An ordered logit model was used to estimate satisfaction with biodiesel for those agencies that use it. For this model, the dependent variable is the degree to which the agency is satisfied with their use of biodiesel, and it ranges from 1 to 5 , with 1 being very dissatisfied and 5 being very satisfied. The explanatory variables include the size characteristics (vehicles, miles, hours), whether the agency operates in an urban or rural area, the number of years the agency has used the fuel, whether the agency provided any biodiesel-specific training, whether they change the blend during colder months, and the percentage of the fleet that uses biodiesel. It is 
hypothesized that larger agencies may have more resources to successfully adopt the new fuel and that those agencies that have more experience using biodiesel, provided training to employees, change the blend during colder months, and operate a higher percentage of the fleet on biodiesel are more likely to have success with the fuel, as defined by how satisfied they are with the fuel. Agencies that operate a higher percentage of their fleet with biodiesel are making a greater commitment to the fuel and, therefore, may be more successful. Previous research of CNG users found that those agencies with a higher percentage of their fleet operating on natural gas were more likely to have success with the fuel (Eudy 2002).

Many of the results were found to be statistically insignificant (Table 3). Two statistically significant results were found. Agencies with a greater number of vehicles and those that operate a greater percentage of their fleet with biodiesel were found to be more likely to have positive experiences with the fuel.

\section{Table 3. Factors Affecting Satisfaction with Biodiesel Use, Results from Ordered Logit Model}

\begin{tabular}{|l|c|c|}
\hline & OR & $\mathbf{9 5 \% ~ C l}$ \\
\hline Vehicles (number) & $1.119^{* *}$ & $1.022-1.225$ \\
\hline Vehicle miles (thousand) & 0.998 & $0.993-1.002$ \\
\hline Vehicle hours (thousand) & 0.983 & $0.942-1.027$ \\
\hline Urban & 0.059 & $0.001-13.54$ \\
\hline Years of experience & 0.662 & $0.365-1.202$ \\
\hline Training & 0.348 & $0.012-9.769$ \\
\hline Change blend & 6.000 & $0.508-70.85$ \\
\hline Percentage of fleet & $1.070^{* *}$ & $1.015-1.128$ \\
\hline $\mathrm{n}=20$ & & \\
\hline
\end{tabular}

Note: $\mathrm{OR}=$ odds ratio; $\mathrm{Cl}=$ confidence interval. ${ }^{*} p<0.10{ }^{* *} p<0.05{ }^{* * *} p<0.01$

There are a few possible explanations for how the percentage of fleet dedicated to biodiesel is related to satisfaction. One explanation is that fleets with a higher percentage of vehicles operating on an alternative fuel have a greater familiarity with the fuel and are better equipped to handle any difficulties. Another explanation is that agencies with positive experiences could be more likely to expand their use of the alternative fuel. Alternatively, agencies that commit to an alternative fuel may feel the need to justify that decision by overestimating the positive benefits. 
This result does not mean that smaller agencies or rural agencies cannot or do not have success with biodiesel. A number of factors can contribute to the success agencies have with adopting new fuels or new technologies, and a lot can be learned from the smaller, rural systems that have had success.

Attempts were made to model satisfaction with hybrid vehicles, but no significant results were found, possibly due to limited data. Alternatively, it could be that those agencies dissatisfied with hybrid vehicles were largely unique cases that could not have been predicted by any agency characteristics or other factors. Similar models were not applied to other alternatives due to limited data.

\section{Conclusion}

Previous research has identified advantages and disadvantages from using alternative fuels and hybrid buses. However, less is known about the factors that motivate agencies to adopt these alternatives or the degree to which different deterrents prevent adoption, especially among small urban and rural transit agencies. In this study, survey responses from 115 transit systems in small urban and rural areas were received and analyzed.

Larger agencies and those operating in urban areas were found to be more likely to adopt alternatives than smaller, rural providers. It was also found that beliefs about benefits and deterrents have some influence on adoption. In general, users tended to be more likely to identify benefits. In particular, users of biodiesel, CNG, and hybrid vehicles were more likely to think that improved public perception is a major benefit. Regarding deterrents, non-users were substantially more likely to view infrastructure costs and adequate fuel supply as deterrents for biodiesel; vehicle costs, development of new fuel infrastructure, modifications to maintenance facilities, adequate fuel supply, and maintenance issues as deterrents for CNG; and vehicle availability, depot modification costs, concerns about reliability, and battery replacement costs as deterrents for hybrids.

Findings from a logit model of biodiesel and hybrid adoption indicated that beliefs about the benefits of emissions reductions, improved public perception, and costs savings were the greatest motivating factors for adoption, and concerns about infrastructure costs and fuel supply were the most likely to negatively influence the decision to adopt.

Additional research could investigate whether the perceived deterrents are valid. The deterrents may be valid in some areas and less valid elsewhere. For example, 
concerns by biodiesel non-users about infrastructure costs suggest a misperception about required investments. Providing more and better information to transit providers may reduce possible misperceptions and increase adoption rates.

The survey revealed a general satisfaction with use of alternative fuels and hybrid vehicles for those agencies that have adopted them, though some problems were identified. Significant deterrents also exist for many of the agencies that have not adopted any of these alternatives. Use was much less common in rural areas, and these deterrents would have to be addressed before widespread adoption occurs.

\section{References}

Alvarez, Robert, Peter Schlienger, and Martin Weilenmann. 2010. Effect of hybrid system battery performance on determining $\mathrm{CO} 2$ emissions of hybrid electric vehicles in real-world conditions. Energy Policy 38: 6919-6925.

Beer, Tom, Tim Grant, David Williams, and Harry Watson. 2002. Fuel-cycle greenhouse gas emissions from alternative fuels in Australian heavy vehicles. Atmospheric Environment 36: 753-763.

Eudy, L. Natural Gas in Transit Fleets: A Review of the Transit Experience. Golden, CO: National Renewable Energy Laboratory, 2002.

Federal Transit Administration. 2006. Alternative fuels study: A report to Congress on policy options for increasing the use of alternative fuels in transit vehicles. U.S. Department of Transportation.

Federal Transit Administration. 2007. Transit bus life cyle cost and year 2007 emissions estimation. U.S. Department of Transportation.

Humburg, D. S., T. J. Hansen, L. G. Schumacher, G. L. Mahapatra, G. L. Taylor, and B. T. Adams. 2006. Biodiesel use and experience among state DOT agencies. Applied Engineering in Agriculture 22(2): 177-184.

Mattson, Jeremy. 2012. Use of alternative fuels and hybrid vehicles by small urban and rural transit systems. DP-250, Upper Great Plains Transportation Institute, North Dakota State University.

Nylund, Nils-Olof, Kimmo Erkkila, Maija Lappi, and Markku Ikonen. 2004. Transit bus emission study: Comparison of emissions from diesel and natural gas buses. VTT Processes. 
Ripplinger, David, and Bethany Brandt-Sargent. 2010. Technology adoption by small urban and rural transit agencies. Departmental Report No. 226, Upper Great Plains Transporatation Insitute, North Dakota State University.

Texas Transportation Institute. 2007. Alternative fuel vehicles at small urban and rural public transportation systems in Texas. White Paper, sponsored by the Texas Department of Transportation, College Station, TX: The Texas A\&M University.

\section{About the Author}

JeREMY MATTSON (jeremy.w.mattson@ndsu.edu) is an Associate Research Fellow with the Small Urban \& Rural Transit Center, a program of the Upper Great Plains Transportation Institute at North Dakota State University. He has conducted research on alternative fuels, energy prices, transit ridership, rural intercity transportation demand, and transportation issues related to aging, disabilities, and access to health care and is currently in the Transportation and Logistics Ph.D. program at North Dakota State University. 